\title{
Methods for Disinfection of Hands and Operation Sites
}

\author{
E. J. L. LOWBURY,* D.M. ; H. A. LILLY,* F.I.M.L.T. ; J. P. BULL,* M.D.
}

Brit. med. F., 1964, 2, 531-536

In previous studies we compared the relative value of alternative methods for disinfecting the hands of nurses and surgeons and the skin of operation sites, but a number of relevant questions were not considered. For disinfection of the operation site alcoholic solutions of chlorhexidine $(0.5 \%)$ and iodine $(1 \%)$ were found to be equally effective and superior to a number of other agents (Lowbury, Lilly, and Bull, 1960), but we did not include laurolinium acetate, which was later reported by Verdon (1961) to be more effective than nine other antiseptic preparations, including $1 \%$ iodine in alcohol ; nor did we examine the removal of spore-bearing organisms. In studies on the disinfection of hands we confirmed the cumulative effect of repeated use of hexachlorophane detergent preparations, obtaining the best results with a liquid soap, and found some alternative methods which had comparable effects in reducing the hand flora and in preventing the emergence of bacteria through holes in rubber gloves (Lowbury and Lilly, 1960; Lowbury, Lilly, and Bull, 1963); we also assessed the value of ablution and disinfection in removal of transient flora (Lowbury, Lilly, and Bull, 1964). We did not examine the effects of varying the time of disinfection, of repeated treatments with antiseptics other than hexachlorophane, of varying the medium in which the antiseptic was mixed and the method by which it was applied.

Experiments to fill some of these gaps are described below. In the light of these and previous experiments the choice of methods of skin disinfection suitable for various purposes in hospital and elsewhere are discussed.

\section{Comparison of Laurolinium with Other Methods for Disinfection of Operation or Injection Sites}

In the following experiment we compared the effectiveness of three preparations of laurolinium acetate (4-aminoquinaldinium-1-lauryl acetate monohydrate), of an iodophor (povidoneiodine), and of $0.5 \%$ alcoholic chlorhexidine digluconate in the removal of bacteria from the skin.

\section{Materials and Methods}

Antiseptic Preparations.-The following preparations were tested: (1) providone-iodine ("betadine") antiseptic solution ; (2) chlorhexidine (" hibitane") digluconate, $0.5 \%$, in $70 \%$ ethyl

* From the Medical Research Council Industrial Injuries and Burns Research Unit, Birmingham Accident Hospital. alcohol ; (3) laurolinium acetate ("laurodine"), $5 \%$, in $70 \%$ ethyl alcohol ; (4) $5 \%$ aqueous laurolinium acetate solution; (5) laurolinium skin spray, an aerosol dispersed from a pressure pack containing laurolinium acetate $(5 \% \mathrm{w} / \mathrm{v})$ in industrial spirit (50 g.) with propellants (50 g.); and (6) control treatment: no antiseptic preparation.

Application of Antiseptics.-Preparations 1, 2, 3, and 4 were applied with a gauze swab to the whole surface of both hands, and reapplied when necessary so that the skin was kept moist for approximately two minutes. In using laurolinium skin spray the whole surface of both hands was sprayed with the aerosol and kept moist for two minutes by repeated spraying.

Testing the Antiseptic Preparations.-The effectivenss of skin disinfection was assessed by a method described in detail elsewhere (Lowbury et al., 1960). Viable counts of bacteria were obtained from standard hand-washings taken before and again after the application of the antiseptic. A Latin-square design was used for the experiment, each of the five preparations and a control treatment (rinsing briefly under a tap) being tested on each of six subjects; the six replicate testings were made on one day in alternate weeks to allow the skin flora to return to its normal level between tests. Both sampling fluid (Ringer's solution) and culture medium (pour-plates of nutrient agar) contained neutralizers-“lubrol W" $(1 \%)$, lecithin $(0.5 \%)$, "tween 80 " (1\%), and sodium thiosulphate (1\%)-and tests were made in each experiment for transfer of inhibitory amounts of antiseptic. The effect of treatment was assessed by a comparison of viable bacterial counts from the first and second samplings; the bacterial counts were made after 48 hours' incubation of the pour-plates at $37^{\circ} \mathrm{C}$

\section{Results}

The reduction in bacterial counts of hand-washings taken after various forms of treatment expressed as a percentage of the initial (pretreatment) counts is shown in Table I, and analysis of variance in the experiment is shown in Table II. There was a marginally significant variance due to differences

\begin{tabular}{l} 
TABle II.-Disinfection of Operation Site: Analysis of Variance \\
\hline
\end{tabular}

TABlE I.-Disinfection of Operation Site: Reduction in Bacterial Counts from Hand-washings Expressed as Percentage of Initial Count

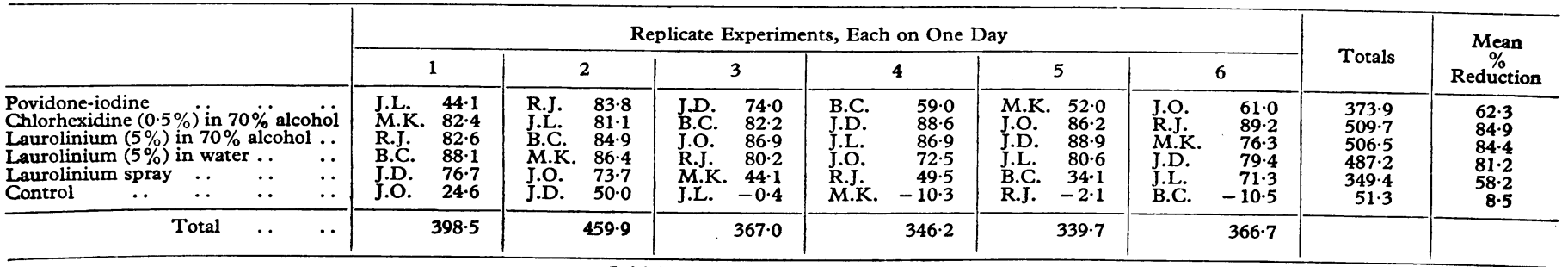

Initials indicate experimental subjects. 
vetween days and individuals, apparently caused by the large reduction in bacterial counts after the control treatment in one subject (J. D.). In the comparison between different methods of treatment, chlorhexidine in alcohol, laurolinium in alcohol, and aqueous laurolinium were not significantly different from each other, but all were significantly better than povidoneiodine, laurolinium spray, and control treatment. Povidoneiodine and laurolinium spray were not significantly different from each other in their skin-disinfecting action, but both were significantly better than the control treatment.

The mean reduction of skin flora by alcoholic chlorhexidine in this study $(84.9 \%)$ was similar to that $(81.3 \%)$ found in our previous study (Lowbury et al., 1960); the mean reduction by alcoholic laurolinium was in the same range $(84.4 \%)$, and aqueous laurolinium was found to be approximately as effective as alcoholic laurolinium (mean reduction of skin flora $=81.2 \%$ ).

\section{Disinfection by Alcoholic Chlorhexidine after Repeated Ablutions with Hexachlorophane Detergent Cream}

Repeated ablution with hexachlorophane detergent cream or soap has been shown to cause a large progressive reduction in skin flora, but appreciable numbers of bacteria can usually be isolated from hand-washings even after two or three days' consistent use of such agents-for example, Lowbury et al. (1963). If pre-operative preparation with alcoholic chlorhexidine or laurolinium were shown to have as great a proportionate effect on skin treated repeatedly with hexachlorophane as on untreated skin, it should be possible to reduce the resident flora to a negligible level. The following experiment was made.

Materials and Methods.-Nine subjects were provided with hexachlorophane detergent cream ("phisohex"), with which they washed their hands in a standard manner for two minutes, four times on each of two successive days and once on the third day. Before and after the first ablution and again after the ninth ablution bacteriological samples were taken from the hands by a standard hand-washing technique in a bowl of sterile Ringer's solution containing neutralizers, from which pourplate cultures were inoculated (see Lowbury et al., 1963). After the third sampling the skin of both hands was disinfected, as for an operation, by application of chlorhexidine gluconate $(0.5 \%)$ in $70 \%$ alcohol on a gauze swab, the skin being kept moist with the antiseptic for two minutes. It was then allowed to dry, and a further bacteriological sample was taken. Tests for transfer of inhibitory concentrations of antiseptic to rinsing fluids and to culture plates were made by duplicate inoculation of a culture of Staphylococcus aureus on these media and on control media.

Results.-The individual and the mean percentage survival of bacteria after these forms of treatment are summarized in Table III. As in previous studies, the immediate effect of one application of the hexachlorophane preparation was negligible, but repeated use led to a large fall in bacterial counts. The

TABLE III.-Effect of Repeated Disinfection of Hands with Hexachlorophane Detergent Cream Followed by Treatment with Alcoholic Chlorhexidine Solution

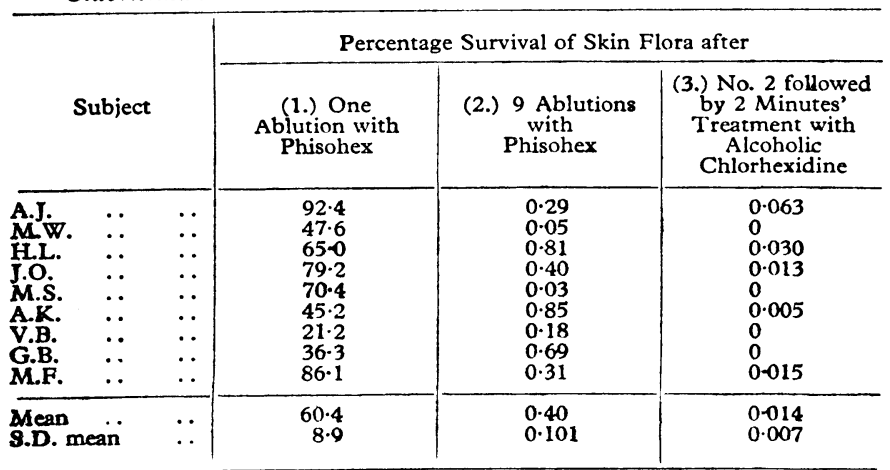

further mean reduction in skin flora after the additional treatment with alcoholic chlorhexidine (96.5\%) was no less than that obtained by disinfecting unprepared skin with chlorhexidine in alcohol (see Table I): from four of the nine subjects in the experiment no bacteria were found in $10-\mathrm{ml}$. amounts of bacteriolngical hand-washings taken after the last treatment.

\section{Effect of Varying Time of Exposure to Skin Antiseptics}

Material and Methods.-Tests were made with the following agents: (1) chlorhexidine gluconate $(0.5 \%)$ in $70 \%$ alcohol (replicate tests on eight subjects); (2) chlorhexidine diacetate $(0.5 \%)$ in water (replicate tests on eight subjects) ; (3) laurolinium (5\%) in $70 \%$ alcohol ; and (4) laurolinium $(5 \%)$ in water (replicate tests on two subjects). Both hands were disinfected by rinsing in $100 \mathrm{ml}$. of antiseptic solution; a standard procedure was used, including a constant number of strokes with palm to palm, palm over dorsum, and with fingers interlaced. After 30 seconds, 60 seconds, 90 seconds, and 120 seconds of this disinfecting procedure the bacterial flora of the hands was sampled by a standard hand-washing technique (Lowbury et al., 1963) in Ringer's solution containing neutralizers ; after each sampling the hands were rinsed under running water. Pour-plates were prepared from the hand-washings (with nutrient agar containing neutralizers), and viable counts

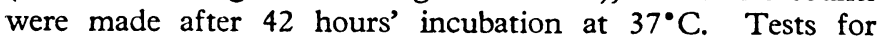
carry-over of antiseptics to sampling fluid and to culture medium were made. In the tests with preparation 3 there was considerable inhibition of growth by transfer of antiseptic to culture medium, and no further study was made with this material.

Results.-The results of tests with preparations 1 and 2 are shown in Table IV. In most of the tests the major part of the skin disinfection had been attained after 30 seconds' treatment, but longer treatment removed more organisms. Alcoholic chlorhexidine showed slightly but not significantly less activity than aqueous chlorhexidine in 30 seconds, but after longer intervals results were approximately the same with both agents, and none of the observed differences was significant. In a more limited experiment aqueous laurolinium showed slightly less activity than the chlorhexidine solutions at 30 seconds and at 2 minutes. An unexpected finding was the larger reduction in skin flora when the antiseptic solution was applied by the standard rinsing method than when it was applied, as on an operation site, with a gauze swab (see Lowbury et al., 1960, and above), or than when it was applied in a timed but unstandardized rinse (see Table VI).

TABLE IV.-Period of Disinfection and Removal of Skin Flora

\begin{tabular}{|c|c|c|c|c|c|}
\hline \multirow[t]{2}{*}{ Treatment } & \multirow[t]{2}{*}{$\begin{array}{l}\text { Sub- } \\
\text { jects }\end{array}$} & \multicolumn{4}{|c|}{$\begin{array}{c}\text { Mean Percentage Reduction in Bacterial } \\
\text { Counts of Hand Washings after Disinfection } \\
\text { for }\end{array}$} \\
\hline & & 30 Seconds & 60 Seconds & 90 Seconds & 120 Seconds \\
\hline $\begin{array}{l}\text { Alcoholic chlorhexidine } \\
(0.5 \%) \\
\text { Aqueous chlorhexidine } \\
(0.5 \%) \\
\begin{array}{rrr} & . & \ldots\end{array}\end{array}$ & $\begin{array}{l}8 \\
8\end{array}$ & $\begin{array}{l}84 \cdot 8 \pm 12 \cdot 3 \\
90 \cdot 0 \pm 7 \cdot 2\end{array}$ & $\begin{array}{l}95 \cdot 1 \pm 6 \cdot 5 \\
94 \cdot 0 \pm 5 \cdot 3\end{array}$ & $\begin{array}{l}97 \cdot 8 \pm 1 \cdot 9 \\
95 \cdot 7 \pm 3 \cdot 9\end{array}$ & $\begin{array}{l}99 \cdot 0 \pm 1 \cdot 4 \\
98 \cdot 2 \pm 10 \cdot 4\end{array}$ \\
\hline
\end{tabular}

\section{Comparison of Antiseptic Rinses and Creams}

In previous experiments (Lowbury et al., 1963) we found that two antiseptics, chlorhexidine and "hycolin," were ineffective in removing resident organisms when applied repeatedly in a cream to the dry skin ; experiments made with hycolin liquid soap showed that this caused a significant reduction in skin flora. A further comparison of cream and aqueous solution as vehicles for antiseptics was therefore made.

Materials and Methods.-The following preparations were studied: (1) chlorhexidine (1\%) hand cream; (2) a solution of chlorhexidine diacetate $(0.5 \%)$ in water ; (3) a cream con- 
taining hexachlorophane $(0.5 \%)$; (4) a cream containing no antiseptic ; and (5) control treatment-no antiseptic. In using the creams the hands were washed with ordinary bar soap and water, and dried on a sterile towel. A small amount (about 1 in. $(2.5 \mathrm{~cm}$.) from a tube) of the cream was rubbed thoroughly into the whole surface of both hands until they felt comfortably dry. Chlorhexidine solution was used for a 30-second rinsing (free style) of both hands, followed by rinsing under a tap and drying on a sterile towel. Before each treatment and also in the controls the hands were washed briefly with ordinary bar soap and water. A Latin-square design was used for the experiment, five subjects receiving each treatment. In each of the five replicates of the experiment the subjects' hands were washed and sampled in the manner described elsewhere (Lowbury et al., 1963) for viable counts of skin flora on a Monday ; on Tuesday and again on Wednesday the hands were treated six times with the selected preparation; on Thursday a second sampling for viable skin flora was made. Experiments were made in alternate weeks to allow a restoration of normal skin flora between tests on the same individuals.

Results.-Table $\mathrm{V}$ shows the mean viable counts of bacteria from hand-washings and the analysis of variance of log counts in the experiment. The repeated rinses with chlorhexidine were very significantly effective, but the creams containing chlorhexidine and hexachlorophane were not significantly more effective than the control cream or the untreated control.

TABLE V.-Effect of Vehicle on Skin Disinfection by Chlorhexidine and Hexachlorophane (Viable Count of Bacteria from $0.1 \mathrm{ml}$. of Handwashings)

\begin{tabular}{|c|c|c|c|c|c|c|}
\hline & \multirow[b]{2}{*}{ Day } & \multicolumn{5}{|c|}{ Preparations Used for Hand Treatment } \\
\hline & & $\begin{array}{c}\text { Chlor- } \\
\text { hexidine } \\
\text { Cream }\end{array}$ & $\begin{array}{c}\text { Hexa- } \\
\text { chlorophane } \\
\text { Cream }\end{array}$ & $\begin{array}{c}\text { Chlor- } \\
\text { hexidine } \\
\text { Rinse }\end{array}$ & $\begin{array}{l}\text { Control } \\
\text { Cream }\end{array}$ & Control \\
\hline $\begin{array}{l}\text { Mean counts of } \\
5 \text { experiments }\end{array}$ & $\begin{array}{l}1 \\
4\end{array}$ & $\begin{array}{l}163 \\
164\end{array}$ & $\begin{array}{l}154 \\
129\end{array}$ & $\begin{array}{r}475 \\
5\end{array}$ & $\begin{array}{l}183 \\
271\end{array}$ & $\begin{array}{l}195 \\
319\end{array}$ \\
\hline \multicolumn{7}{|c|}{ Analysis of Variance (Log Counts) } \\
\hline & \multicolumn{2}{|c|}{$\begin{array}{l}\text { Degrees of } \\
\text { Freedom }\end{array}$} & $\begin{array}{l}\text { Sum of } \\
\text { Squares }\end{array}$ & $\begin{array}{c}\text { Mean } \\
\text { Squares }\end{array}$ & \multicolumn{2}{|c|}{ Significance } \\
\hline $\begin{array}{lc}\text { Experiment } & . \\
\text { Person } & : \\
\text { Treatment } & : \\
\text { Residual } & .\end{array}$ & \multicolumn{2}{|r|}{$\begin{array}{r}4 \\
4 \\
4 \\
12\end{array}$} & $\begin{array}{r}1.1815 \\
0.7433 \\
18.3569 \\
2.2988\end{array}$ & $\begin{array}{l}0.2954 \\
0.1858 \\
4.5892 \\
0.1916\end{array}$ & \multicolumn{2}{|c|}{$\begin{array}{c}\text { NS } \\
\text { Significant }\end{array}$} \\
\hline
\end{tabular}

\section{Continued Action of Antiseptics after Ablution}

A hexachlorophane detergent ablution has been shown to have little immediate effect, but when rubber gloves are worn for an hour after a single ablution with such an agent the skin flora is shown to be considerably reduced (Lowbury et al., 1963). This effect has been attributed to the persistence of residues of the slow-acting antiseptic on the skin (Fahlberg, Swan, and Seastone, 1948).

The following experiment was made to determine whether povidone-iodine, which has a similar cumulative skindisinfecting action to that of hexachlorophane (Lowbury et al., 1963), owes this property to the continued action by residues of the antiseptic left on the skin after ablution.

Method.-The viable counts of bacteria on the hands of six subjects were assessed by the method described previously (Lowbury et al., 1963) (a) before treatment, (b) immediately after a standard two minutes' hand-wash with povidone-iodine and water, and (c) (in a separate experiment) after wearing rubber gloves for one hour after the ablution with povidoneiodine.

Result.-The mean percentage reduction in bacterial counts of skin samples immediately after the treatment with povidoneiodine was $74.3 \%$; after wearing gloves for one hour following treatment with povidone-iodine, the mean percentage reduction in bacterial counts compared with those obtained before treat- ment was $80.3 \%$. No important further action by povidoneiodine on skin flora after the ablution could therefore be detected.

\section{Effect of Single and of Repeated Rinses with Chlorhexidine Solution}

To test the possibility of cumulative or progressive skin disinfection by repeated rinses with chlorhexidine solution we made the following experiment.

Materials and Methods.-Four.subjects were chosen for the experiment. After a quick "social" hand-wash the hands were sampled by a standard hand-washing test for viable counts of bacteria. The hands were then rinsed in an aqueous solution of chlorhexidine diacetate for 30 seconds ("free style" rinsing), and sampled again for viable counts of bacteria. In the next two days the four subjects rinsed their hands 12 times (six times a day) in the same manner with chlorhexidine solution. On the morning after the last chlorhexidine rinse a third series of samples for viable counts was taken from the hands of the four subjects.

Results.-The percentage reduction of bacterial counts in this experiment is shown in Table VI. There was a large variance

TABLE VI.-Effect of Repeated Rinsing of Hands with Aqueous Chlorhexidine Solution

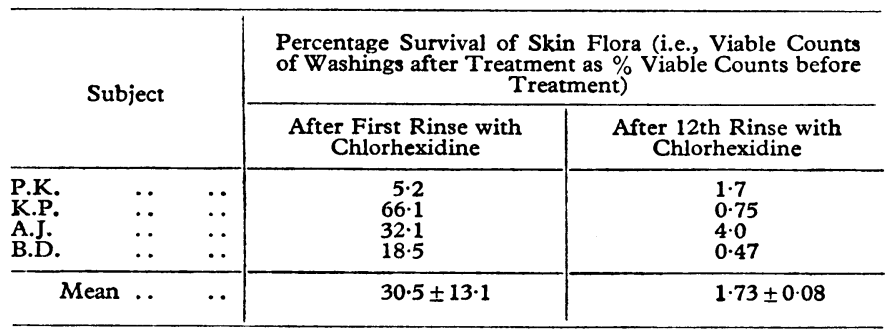

in the residual flora after one treatment, but a consistent large further reduction in the mean viable counts of hand-washings to less than $2 \%$ of the initial mean counts after a series of treatments with chlorhexidine solution.

\section{Effect of Repeated Rinsing on Activity of Chlorhexidıne Solution}

To assess the possible depletion of antiseptic activity from bowls of chlorhexidine solution used by nurses for hand-rinsing we made the following experiment.

Method.-A bowl containing 2 litres of $0.5 \%$ aqueous chlorhexidine diacetate solution was used for rinsing the hands of laboratory staff. Before rinsing in the antiseptic solution the hands were washed with soap and water and rinsed under a running tap, but not dried. The minimal inhibitory concentration of the rinsing water was tested with a strain of Staph. aureus before use, after 15 rinses, and again after 30 rinses.

Result.-The rinsing fluid became turbid, but there was no reduction in its activity. No bacterial growth was obtained on subculture of the fluid to a large volume of medium containing neutralizers.

\section{Removal of Bacterial Spores from the Skin of Operation Sites}

Because of their resistance to most antiseptics, the spores of Clostridium tetani and other sporing pathogens are usually considered insusceptible to skin disinfection, and reliance is placed entirely on physical ablution with soap or detergent and water. Iodine is more active against spores than other antiseptics used for skin disinfection, but in the form of a tincture or an aqueous solution with potassium iodide it is too irritant to 
be left moist on the skin for more than a very short period ; in the complexes of iodine with solubilizers, known as iodophors -for example, povidone-iodine-iodine retains its bactericidal and sporicidal activity, but does not stain the skin, and is claimed to be free from sensitizing or irritant properties (Gershenfeld, 1957, 1962 ; Joress, 1962 ; Davis, 1962).

The following experiments were made to determine how much sporicidal action could be obtained by the application of povidone-iodine to the skin.

\section{Sporicidal Action of Povidone-iodine Applied to the Skin}

Materials and Methods.-A strain of Bacillus subtilis var. globigii (BSG 63/1) was grown in nutrient broth at $37^{\circ} \mathrm{C}$. After overnight incubation the culture was washed and resuspended in sterile distilled water, and heated at $56^{\circ} \mathrm{C}$. for one hour. Examination of a stained film of the suspension showed spores in 70 to $80 \%$ of the bacilli. Viable counts of suspension heated at $56^{\circ} \mathrm{C}$. for one hour and at $80^{\circ} \mathrm{C}$. for 10 minutes were approximately the same. On measured circular areas of the skin of the forearm of volunteers, $0.02 \mathrm{ml}$. (1 drop) of the suspension of $B$. subtilis var. globigii was inoculated with a calibrated dropping-pipette and spread over the whole area with a wire loop. When dry these areas were covered with compresses of lint soaked and kept moist with povidone-iodine antiseptic solution for periods of $15,30,60,90$, and 120 minutes. Control areas of skin were covered with compresses soaked and kept wet with distilled water. From these areas samples were taken for viable counts by rubbing in a standard way for 15 seconds with a glass spreader under $5 \mathrm{ml}$. of sterile Ringer's solution containing neutralizers (including sodium thiosulphate), the solution being kept in place by a truncated glass cylinder (Story, 1952 ; Lowbury et al., 1960).

Results.-Povidone-iodine compresses were found to reduce the numbers of viable sporing bacilli on the skin by $99.85 \%$ in 60 minutes (Table VII) ; the absence of any such reduction after application of water compresses showed that this effect was due almost entirely to the action of the antiseptic, not to mechanical removal by the compress.

TABLE VII.-Removal of $B$. subtilis var. globigii Spores from Skin by Povidone-iodine (P.V.I.)

\begin{tabular}{|c|c|c|c|c|c|c|}
\hline \multirow{3}{*}{$\begin{array}{l}\text { Minutes } \\
\text { of } \\
\text { Exposure } \\
\text { to P.V.I. } \\
\text { or Control } \\
\text { Compresses }\end{array}$} & \multicolumn{6}{|c|}{$\begin{array}{l}\text { Viable Counts of } B \text {. subtilis in Washings from Skin as \% Counts } \\
\text { of Initial W' ashings taken when no Compress had been Applied }\end{array}$} \\
\hline & \multicolumn{2}{|c|}{ Experiment 1} & \multicolumn{2}{|c|}{ Experiment 2} & \multirow{2}{*}{$\begin{array}{l}\text { Experi- } \\
\text { ment } 3 \\
\text { (P.V.I.) }\end{array}$} & \multirow{2}{*}{$\begin{array}{l}\text { Experi- } \\
\text { ment 4 } \\
\text { (P.V.I.) }\end{array}$} \\
\hline & P.V.I. & Control & P.V.I. & Control & & \\
\hline $\begin{array}{r}15 \\
30 \\
60 \\
90 \\
120\end{array}$ & $\begin{array}{l}0.26 \\
0.15 \\
0.05 \\
0.06 \\
0.05\end{array}$ & $\begin{array}{l}30 \\
40 \\
= \\
=\end{array}$ & $\begin{array}{l}1 \cdot 13 \\
0.47 \\
0 \cdot 32 \\
0 \cdot 21 \\
0.02\end{array}$ & $\begin{array}{l}68 \\
76 \\
= \\
=\end{array}$ & $\begin{array}{l}0.60 \\
0.47 \\
0.33 \\
0.15 \\
0.13\end{array}$ & $\begin{array}{l}1.56 \\
2.17 \\
1.17 \\
0.42 \\
0.14\end{array}$ \\
\hline
\end{tabular}

\section{Comparison of Sporicidal Action by Povidone-iodine on B. Subtilis Var. Globigii and on $\mathrm{Cl}$. Welchii}

To assess the probable usefulness of povidone-iodine in removing a pathogenic sporing organism we compared the survival of $B$. subtilis var. globigii, our test organism in the study on skin disinfection, with a sporing culture of $\mathrm{Cl}$. welchii $(63 / 2)$.

Materials and Methods.-A broth culture of B. subtilis var. globigii and a sporing culture of $\mathrm{Cl}$. welchii, produced by growing a strain of the organism in Ellner's (1956) medium, were washed and resuspended in distilled water. On microscopical examination, approximately 70 to $80 \%$ of the $B$. subtilis var. globigii and $80 \%$ of the $C l$. welchii cells contained spores. Viable counts of the suspensions were made by the method of Miles, Misra, and Irwin (1938) on the untreated suspensions, and on mixtures of $0.1 \mathrm{ml}$. of the bacterial suspension with $5 \mathrm{ml}$. of povidone-iodine antiseptic solution which had been allowed to stand, after mixing, for periods from 5 to 150 minutes.

Results.-Table VIII shows that the spores of $\mathrm{Cl}$. welchii were at least as sensitive to the killing action of the iodophor as those of B. subtilis var. globigii. Neither strain showed any evidence of a sporicidal effect after five minutes' exposure to the antiseptic, but after 15 minutes the counts of both organisms were reduced to less than $0.1 \%$.

TABLE VIII.-Survival of Spores of $\mathrm{Cl}$. welchii and of B. subtilis var. globigii in Presence of Povidone-iodine

\begin{tabular}{c|r|r}
\hline \multirow{2}{*}{$\begin{array}{c}\text { Time of Exposure } \\
\text { (Minutes) }\end{array}$} & \multicolumn{2}{|c}{$\begin{array}{c}\text { Viable Counts per ml. of Spore Suspensions after Exposure } \\
\text { to Povidone-iodine }\end{array}$} \\
\cline { 2 - 3 } & Cl. voelchii & B. subtilis var. globigii \\
\hline 0 & $4,800,000$ & $3,600,000$ \\
5 & $3,800,000$ & $3,700,000$ \\
15 & 1,000 & 3,100 \\
30 & 57 & 2,200 \\
60 & 38 & 480 \\
90 & 29 & 23 \\
120 & 18 & 5 \\
150 & 0 & 3 \\
\hline
\end{tabular}

\section{Discussion}

The experiments described above are relevant both to surgeons' and nurses' hands and to the patient's operation site. In the comparison of alternative methods for disinfecting the operation site, for example, it was shown that alcoholic chlorhexidine, alcoholic laurolinium, and aqueous laurolinium were of approximately equal value, but a laurolinium spray was less effective. This confirmed the view that rubbing an antiseptic on to the skin enhances its value (cf. Price, 1957). The same conclusion is suggested by the finding that chlorhexidine in alcohol applied on a swab (see Table I ; also Lowbury et al., 1960) caused a smaller reduction of the skin flora than rinsing the hands with a standard procedure of rubbing palm to palm, palm over dorsum, and with fingers interlaced (see Table IV). The precise technique of rinsing also appears to affect the results, as shown in the greater reduction of skin flora by aqueous chlorhexidine solution when the hands were rinsed for 30 seconds in a standard manner described above than when they were rinsed for the same time but in a random manner (see Table VI).

Practical periods of disinfection vary with clinical circumstances ; for example, periods of disinfection shorter than two minutes are usual before injection or venepuncture, and our study on the relation of disinfecting-time to removal of skin flora showed that treatment with alcoholic chlorhexidine or laurolinium for 30 seconds was slightly less effective than for two minutes. The difference between the effects of treatment in shorter or longer periods of application was smaller with aqueous chlorhexidine, which had almost as good an effect at 30 seconds as it had at two minutes. In an earlier experiment the effect of three successive two-minute rinses with $70 \%$ alcohol was studied (Lowbury et al., 1960) ; the second rinse caused an appreciable further reduction in hand flora, but the third treatment caused little or no reduction beyond that reached in the second rinse. It would seem from these studies that all the accessible organisms are removed in a fairly short period of disinfection. The cumulative effects of repeated disinfection at longer intervals with hexachlorophane soap or chlorhexidine rinses, or (still better) with a combination of these methods, suggests that some of the resident organisms which are inaccessible immediately after skin disinfection become accessible to antiseptics after a while, and before the flora has had a chance to proliferate to its previous level.

The cumulative action of povidone-iodine surgical scrub (Lowbury et al., 1963) and of rinsing with chlorhexidine (as described above) shows that this is not a peculiar property of hexachlorophane, and in the former examples it is not dependent on the attachment of antiseptic to the skin (with action continuing after the hands are rinsed and dried). The peculiar 
feature of hexachlorophane is a slow disinfecting action; rinsing the hands in alcohol or in an alcoholic solution of chlorhexidine immediately after ablution-for example, to achieve the maximum disinfecting action described abovewould remove the hexachlorophane before it had a chance to exert any disinfecting action, and its regular use in this way would invalidate the use of hexachlorophane; but the same objection cannot be raised against repeated use of alcoholic solutions after the use of providone-iodine or chlorhexidine solution, since these agents achieve their full disinfecting action at the time of application.

Spores of $\mathrm{Cl}$. tetani, $\mathrm{Cl}$. welchii, and other pathogens are relatively insensitive to most antiseptics, and reliance is usually placed on repeated ablution with detergents to remove these transient organisms from operation sites. This is difficult to achieve in horny skin with much ingrained dirt. Of the antiseptics used for skin disinfection, iodine has a fairly good sporicidal effect in vitro, but its action is too slow to be of much use in the routine two minutes' pre-operative skin disinfection, and longer application of the tincture or of Lugol's solution is irritant and potentially toxic. The iodophors, however, can be applied for long periods, leaving no stain and apparently causing no irritation. Our tests showed that the application of an iodophor (povidone-iodine) to skin contaminated with a suspension of $B$. subtilis var. globigii spores led to the removal by disinfectant action of a large proportion of these organisms.

In these studies we have distinguished resident from transient organisms as those which are more difficult to remove by ablution or disinfection. Staph. aureus sometimes answers to this description. Hare and Ridley (1958) have shown that Staph. aureus can multiply on the skin of the perineal area, but it is uncertain to what extent this can occur on the hands. Colonization of the skin by Staph. aureus is surprising in the light of experiments which showed that these organisms are killed by unsaturated fatty acids of the skin (Ricketts, Squire, and Topley, 1951). It is possible that individuals vary in respect of the amount of unsaturated fatty acid produced by the skin, or in the presence of factors that inactivate this selfdisinfecting mehanism; these variations may be associated with differences in the ability of the skin to become colonized by Staph. aureus.

\section{Choice of Methods}

From the studies reported here and in our previous papers it is possible to draw some tentative conclusions about the types of skin disinfection appropriate for different purposes.

1. Operation Sites.-When it is necessary to obtain maximum skin disinfection in a single application, as before an emergency operation, chlorhexidine $(0.5 \%)$, iodine $(1 \%)$, or laurolinium $(5 \%)$ in $70 \%$ ethyl alcohol applied for two minutes have about the same activity ; laurolinium has rather a high toxic action on skin cells in tissue culture (J. C. Lawrence, personal communication, 1963) and iodine is known to cause sensitization in some individuals, so alcoholic chlorhexidine is probably a good choice. For shorter periods of disinfection-for example, 30 seconds-aqueous chlorhexidine diacetate $(0.5 \%)$ seems at least as good as the alcoholic solution. Antiseptics should be rubbed in with gauze, not sprayed on.

In " cold" surgery, and particularly when a very high degree of asepsis is required, the cumulative effect of antiseptics applied repeatedly over a period of two to three days is desirable-for example, ablution with hexachlorophane liquid soap or povidone-iodine surgical scrub, three or four times a day for two days-followed by a full pre-operative disinfection with alcoholic chlorhexidine. When the skin contains ingrained soil or road dirt, a compress of povidone-iodine antiseptic solution can be expected to kill a large proportion of the spores of tetanus and gas-gangrene bacilli ; repeated ablution, followed by the application of a compress of povidone-iodine for about 30 minutes is a desirable procedure in the removal of spores from the skin of such patients when operation can be delayed for two or three days.

Before injection or venepuncture $70 \%$ alcohol is generally considered acceptable, but a better disinfection can probably be obtained with chlorhexidine or laurolinium solutions (either alcoholic or aqueous) ; since the time of disinfection is unlikely to exceed 30 seconds, an aqueous solution is possibly better than an alcoholic solution.

2. Hands.-The resident flora of surgeons' and nurses' hands can be maintained at a low level by repeated use-for example, six times a day - of a liquid soap or a detergent cream containing hexacholorophane, or with povidone-iodine surgical scrub. Regular rinsing with aqueous chlorhexidine solution has a similar cumulative effect.

Where the control of cross-infection with Gram-negative bacilli is important-for example, in infants' wards during outbreaks of gastroenteritis, or in burns wards-an antiseptic that is active against these organisms is recommended-for example, rinsing with chlorhexidine solution-but the removal of desquamated epithelium by thorough physical ablution is probably the most important part of the discipline for removal of such transient organisms as pseudomonas, escherichia, and salmonella.

\section{Summary}

In a comparison of five methods for disinfecting the operation site, approximately the same reduction in resident skin flora (81-85\%) was obtained by two minutes' application of chlorhexidine digluconate $(0.5 \%)$ in $70 \%$ alcohol, and of aqueous or alcoholic solutions of laurolinium acetate $(5 \%)$. Treating the skin for two minutes with an aerosol of laurolinum acetate or with povidone-iodine antiseptic solution was less effective.

Hands which had been cleared of a large proportion of the skin flora by repeated washing with a hexachlorophane detergent cream showed a further mean reduction of $96.5 \%$ after two minutes' application of alcoholic chlorhexidine $(0.5 \%)$; after this double treatment four out of nine subjects showed no detectable bacteria in washings of the skin, and the mean estimated reduction in skin flora was $99.98 \%$.

A comparison of different times for rinsing the hands with antiseptics showed nearly as large a reduction of flora after 30 seconds' as after two minutes' treatment.

Antiseptic rinsing with a standard number of strokes to cover all surfaces of the hands was more effective than a free-style method of rinsing.

The application of creams containing hexachlorophane $(0.5 \%)$ and chlorhexidine ( $1 \%$ ) repeatedly to the dry hands did not lead to any reduction of the skin flora.

Repeated rinses with aqueous chlorhexidine diacetate solution $(0.5 \%)$ caused a progressive reduction in the skin flora; the mean percentage of surviving bacteria on the skin after a single rinse was $30.5 \%$ but after 12 rinses it was $1.73 \%$.

In contrast with hexachlorophane preparations, which have no immediate effect but act slowly on the skin after the hands have been dried, povidone-iodine was shown to have virtually all its disinfecting action at the time of application.

Sporing bacilli (B. subtilis var. globigii) were removed from the skin by a compress of povidone-iodine antiseptic solution ; when the compress was kept moist for 15 minutes a mean reduction of $99.1 \%$ of sporing bacilli was obtained.

The choice of antiseptic preparations for disinfection of hands and operation or injection sites is discussed.

We are grateful to Mr. M. D. Wilkins for valuable technical assistance ; to the staff of the M.R.C. Unit for their co-operation; 
to Berk Pharmaceuticals Ltd. for supplies of povidone-iodine; and to Messrs. Allen \& Hanburys for supplies of laurolinium acetate.

\section{REFERENCES}

Davis, J. G. (1962). f. appl. Bact., 25, 195.

Ellner, P. D. (1956). f. Bact., 71, 495.

Fahlberg, W. J., Swan, J. C., and Seastone, C. V. (1948). Ibid., 56, 323. Gershenfeld, L. (1957). Amer. F. Surg., 94, 938.

Gershenfeld, L. (1962). Amer. f. Pharm., 134, 78.

Hare, R., and Ridley, M. (1958). Brit. med. F., 1, 69.
Joress, S. M. (1962). Ann. Surg., 155, 296.

Lowbury, E. J. L., and Lilly, H. A. (1960). Brit. med. F., 1, 1445.

- and Bull, J. P.(1960). Ibid., 2, 1039. (1963). Ibid., 1, 1251.

(1964). Ibid. In press.

Miles, A. A., Misra, S. S., and Irwin, J. O. (1938). F. Hyg. (Camb.), 38, 732 .

Price, P. B. (1957). In Antiseptics, Disinfectants, Fungicides, and Chemical and Physical Sterilization, edited by G. F. Reddish, 2nd ed. p. 409. Kimpton, London

Ricketts, C. R., Squire, J. R., and Topley, E. (1951). Clin. Sci., 10, 89.

Ricketts, C. R., Squire, J. R., and Tople
Story, P. (1952). Brit. med. $¥ ., 2,1128$.

Verdon, P. E. (1961). f. clin. Path., 14, 91.

\title{
Final Report of a Prospective Study of Children whose Mothers had Rubella in Early Pregnancy
}

\author{
MARY D. SHERIDAN,* M.A., M.D., D.C.H.
}

A controlled prospective inquiry regarding the effects of rubella and other virus infections in pregnancy, beginning early in 1950 and ending in December 1952, and sponsored by the Ministry of Health, was fully reported by Manson, Logan, and Loy (1960). The total number of pregnancies complicated by rubella available for analysis was 578 . The controls numbered 5,717. Follow-up of the infants showed that when rubella occurred during the first 16 weeks of pregnancy the incidence of congenital abnormalities in the children was significantly raised. When the infection occurred after the 16th week the incidence of abnormalities in the children of the rubella mothers was no higher than in the controls.

The number of pregnancies complicated by rubella in the first 16 weeks was 279 . Of these, 11 ended in abortion and 11 in stillbirth, and 16 crildren died before 2 years of age, leaving 241 in the original group. A number of medical officers of health continued to send in records of children born in 1953 whose mothers had been notified for rubella before the end of 1952. Since these cases fulfilled the criteria laid down by Logan (1951), a further 18 infants whose mothers had rubella in the first 16 weeks of pregnancy were added to the original group. This gave a final total of 259 children available for assessment at 2 years, by which age it had been anticipated that all major abnormalities would have been diagnosed. This examination is designated No. 1 in Table I.

In order to check the possibility of hitherto unidentified defects, however, full paediatric and otological examination of 57 " early rubella" children and 57 controls living in the London and Middlesex areas was undertaken in 1956-7 by Jackson and Fisch (1958), the children concerned being then between the ages of 3 and 6 years. The results of their inquiry indicated that the proportion of children suffering from significant hearing loss had been underestimated at the original examination. It was therefore considered advisable to extend the inquiry to " early rubella " children living in the rest of the country. Reports for 237 children were received and the results were included in the report of Manson et al. (1960). This examination is designated No. 2 in Table I.

Finally, in order to discover how they developed in later childhood a third inquiry was carried out in 1962, when the children were between the ages of 8 and 11 years. The present paper reports the results of this examination, which is designated No. 3 in Table $I$, in relation to findings of the previous examinations.

- Ministry of Health.

\section{The Report Form}

The medical officers of health were requested to provide the following particulars: (1) Any abnormality of the eyes: visual acuity right and left, distant and near, without and with spectacles if worn. (2) Any abnormality of the ears: hearing right and left for quiet conversational voice without lip-reading at 3 and $10 \mathrm{ft}$. $(0.9$ and $3 \mathrm{~m}$.). Also a full pure-tone audiogram. (3) Condition of the heart as reported by a cardiologist or paediatrician. (4) Intelligence quotient, naming testing scale used. (5) Assessment of the child's emotional development and social behaviour. (6) Any other pathological condition present. (7) Type of school attended.

A total of 227 completed reports were received. Of the remaining 32 , one child had emigrated, the parents of five children refused to participate, and 26 were untraced.

Owing to the wide geographical distribution of cases and the large number of medical examiners concerned, it was inevitable that the reports received were not equally informative, but the general standard of recording was high. Assessment of an abnormality as major or minor on the evidence available sometimes required much thought, and final classification is necessarily the result of my personal judgment. For this reason, and because there were no controls, it proved difficult to submit the very varied information collected to any sophisticated statistical analysis. It has therefore been decided to present it in tabulated form.

The final outcome of this prospective study has confirmed the findings of previous, mainly retrospective, inquiries regarding the special vulnerability to rubella infection of the eyes, ears, and heart of the developing foetus during the first 16 weeks of pregnancy. It does not, however, bear out the very pessimistic evaluations of attendant risks which have sometimes been offered on the basis of retrospective studies. Major abnormalities were present in $33(15 \%)$ children, 20 of whom had more than one abnormality. Minor abnormalities were noted in $37(16 \%)$ children, of whom 9 had another abnormality. In both groups, particularly the latter, it is probable that some of the children included were suffering from conditions unrelated to the rubella infection, although in compiling the tables only those children whose abnormalities were considered from the information available to be certainly or possibly due to rubella have been included. Hence 11 children showing single abnormalities which were either known or thought unlikely to be connected with the maternal rubella infection have been omitted from the tables-that is, two cases of myopia devel- 